Journal of Applied Fluid Mechanics, Vol. 2, No. 2, pp. 43-48, 2009.

Available online at www.jafmonline.net, ISSN 1735-3572, EISSN 1735-3645.

DOI: $10.36884 /$ jafm.2.02.11868

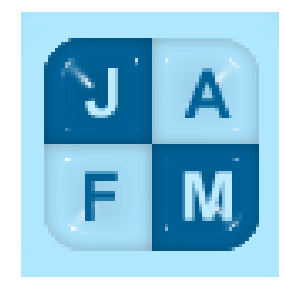

\title{
A Study of DC Surface Plasma Discharge in Absence of Free Airflow: Ionic Wind Velocity Profile
}

\author{
M. Rafika, H. Ramzi and B.N. Sassi \\ National Engineering School of Monastir, Monastir, 5019, Tunisia \\ Email: rafika.mestiri@enim.rnu.tn
}

(Received July 1, 2008; accepted January 21, 2009)

\begin{abstract}
In our study we are interested with the DC (Direct Current) electric corona discharge created between two wire electrodes. We present experimental results related to some electroaerodynamic actuators based on the DC corona discharge at the surface of a dielectric material. We used different geometrical forms of dielectric surface such as a plate, a cylinder and a wing of aircraft of type NACA 0015. We present the current density-electric filed characteristics for different cases in order to determine the discharge regimes. The corona discharge produces non-thermal plasma so that it is called plasma discharge. Plasma discharge creates a tangential ionic wind above the surface at the vicinity of the wall. We have measured the ionic wind induced by the corona discharge in absence of free external airflow, we give the ionic wind velocity profiles for different surface forms and we compare the actuators effect based on the span of the ionic wind velocity values. We notice that the maximum ionic wind velocity is obtained with the NACA profile, which shows the effectiveness of this actuator for the airflow control.
\end{abstract}

Keywords: Electroaerodynamic actuator, ionic wind, corona discharge, dielectric surface.

\section{INTRODUCTION}

Actually different plasma actuators are studied, including DC glow discharge (Kimmel et al. 2004, January), dielectric barrier discharge (DBD) (Corke et al. 2004, January and Roth 2003), radio-frequency glow discharge (Merriman et al. 2001, August) and filamentary arc discharge (Samimy et al. 2004). These actuators are considered for the airflow control which is a very interesting purpose and which has a great importance in aerodynamics. A great number of wellknown aerodynamic applications have been studied. These actuators act on an incompressible fluid flow being the subject of some numerical studies (Rahmati et al. 2009 and Mahanti et al. 2009). The corona discharge may be used as an air-moving mechanism in order to modify the airflow around an obstacle (Léger et al., 2001, Artatna et al., 1999; Desimone et al., 1999 and Artana et al., 2000). An important characteristic of the electroaerodynamic actuators is the tangentially energy injection to the surface, this property justifies the actuators efficiency. Léger et al. (2002) showed through their experimental study of the DC corona discharge, that the ionic velocity at the wall increases with the discharge current and reaches about $3 \mathrm{~m} / \mathrm{s}$. An experimental investigation of the dielectric-barrier-discharge conducted by Forte et al. (2006) showed that an optimization of some plasma actuator parameters may lead to a produced ionic wind with a velocity up to $7 \mathrm{~m} / \mathrm{s}$ at 0.5 $\mathrm{mm}$ of the wall, for a single actuator and $8 \mathrm{~m} / \mathrm{s}$ for multiple actuators. The plasma actuators are used to leading edge separation control on airfoils (Corke et al. 2004, Post et al. 2006 and Patel et al. 2008); it is showed experimentally that they may increase the maximum lift coefficient. Numerical and experimental studies led by $\mathrm{He}$ et al. (2007) showed that the plasma actuators could be effective in controlling the turbulent flow separation. Suchomel et al. (2003, June) provide an overview of different plasma technologies currently under investigation for aeronautical applications. Moreau (2007) talked in his review about worldwide works on flow control methods, such as the use of mechanical flaps, wall synthetic jets or MEMS (Micro-Electro-Mechanical System) and plasma-based devices. He evoked in a first part the electrical and mechanical characterization of the plasma actuators in the absence of a free air stream. Indeed, although many researchers study the effects of plasma actuators on airflow, only a few study the discharge induced electric wind in the absence of free airflow. However, this study seems crucial to be able to optimize and to well know the mechanical effects of such actuators in order to use them efficiently for flow control. Consequently, the goal is to describe briefly the physics and electrical parameters of atmospheric plasmas, and then to focus more particularly on the mechanical effects of the discharge, such as electric wind, induced body force and induced kinetic power. Moreau (2007) evoked, in his review, a second part that deals with the application of plasma actuators for airflow control so he presented the worldwide works on this topic. He said that, regarding the large number of publications, plasma actuators have shown their good efficiency for airflow control at velocities up to $30 \mathrm{~m} / \mathrm{s}$, and some significant results have been obtained up to $110 \mathrm{~m} / \mathrm{s}$ and more. 
In this paper we present our experimental device, we describe our studied configuration, then we give our experimental results based on the electric and mechanic behaviours of the DC corona discharge. In fact, we have used different dielectric support surfaces and different geometry forms for these supports; also we varied the nature of the conductive electrodes. The discharge has a dynamic effect due to the created ionic wind which is also called electric wind. We studied the ionic wind in absence of an external airflow. We show the electrical characteristics given by the curves of the current density versus the electric field and we present the profiles of the ionic wind for different forms of the dielectric surface in order to justify the mechanical effect of our actuators.

\section{EXPERIMENTAL SET UP}

The applied High Voltage (HV) between the two electrodes is delivered by a HV generator. The electrodes are two parallel conductive wires flash mounted at the surface of a dielectric material. The anode, having the lower radius, is submitted to a positive high voltage (from $25 \mathrm{kV}$ to $40 \mathrm{kV}$ ), while the cathode is connected to the ground. The two electrodes have the same length that is equal to $20 \mathrm{~cm}$ for all studied cases. The measurement of the ionic wind is done by a glass "Pitot" tube linked to a micromanometer "Furness Controls". The Pitot tube is made of glass in order not to disrupt the discharge. The outside and inside diameters of the Pitot probe are respectively $8 \mathrm{~mm}$ and $6 \mathrm{~mm}$ and for the probe point they are respectively $2.5 \mathrm{~mm}$ and $1.5 \mathrm{~mm}$. Velocity profiles are obtained while displacing the Pitot tube along the $y$ axis (y axis is of the increasing altitudes) with an automated displacing system. The point of velocity measurement is marked by $\mathrm{x}$ (Fig.1). We have studied four geometrical forms of dielectric surface corresponding to four insulating material types. In the first case the two electrodes are printed at the surface of a positive presensitized epoxy plate used for printed circuits, the anode and cathode diameters are respectively $0.5 \mathrm{~mm}$ and $2 \mathrm{~mm}$ with an electrode gap of $40 \mathrm{~mm}$. In the second case the electrodes are two copper wires encrusted into two grooves at the surface of a Plexiglas (PMMA) flat plate and they are distant with $30 \mathrm{~mm}$, the anode diameter is $0.4 \mathrm{~mm}$ while the cathode has $2 \mathrm{~mm}$ as diameter. The electrodes gap is less important than the previous case so that we bring another case different from what is very studied for the PMMA plate in the literature, so we can draw the effect of the interelectrodes gap. For the third case, the discharge is studied at the surface of a NACA 0015 profile made of wood. It is a symmetric profile, having a chord of $20 \mathrm{~cm}$, a thickness of $3 \mathrm{~cm}$ and its curvature is equal to zero. For this last case, the two electrodes are printed on two $(10 \mathrm{~mm} \times 30 \mathrm{~mm})$ plates having a thickness of $1.5 \mathrm{~mm}$, these two plates are placed into two grooves at the surface of the wood profile. The profile surface wood is covered by a layer of varnish. The anode and the cathode are distant with $40 \mathrm{~mm}$ and they have respectively as diameters $0.5 \mathrm{~mm}$ and $2 \mathrm{~mm}$ (Fig. 1).

The fourth case corresponds to two copper wires placed into two grooves diametrically opposed at the surface of a Teflon (PTFE) cylinder and having diameters of $0.4 \mathrm{~mm}$ and $2 \mathrm{~mm}$ respectively for the anode and the cathode. The internal and external diameters of the PTFE cylinder are respectively 20 $\mathrm{mm}$ and $30 \mathrm{~mm}$. The two electrodes are diametrically opposed, so that their coordinates are: $\mathrm{y}_{\text {anode }}=0 \mathrm{~mm}, \mathrm{y}_{\text {cathode }}=$ $-30 \mathrm{~mm}, \mathrm{x}_{\text {anode }}=0 \mathrm{~mm}$ and $\mathrm{x}_{\text {cathode }}=0 \mathrm{~mm}$.

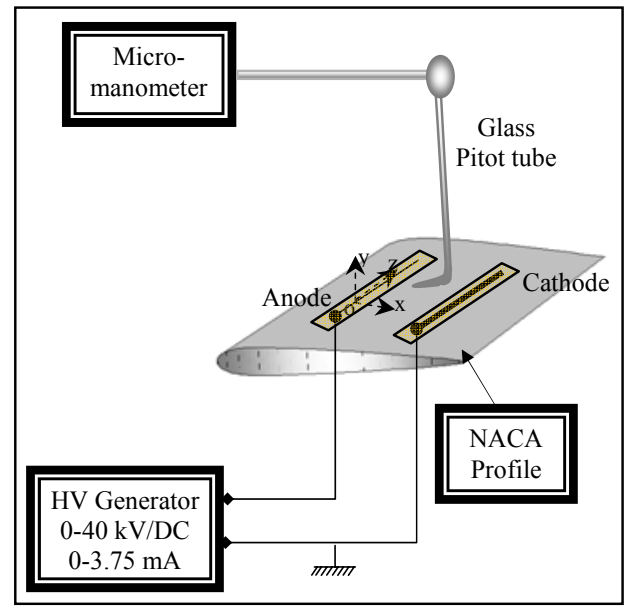

Fig. 1. Scheme of the Experimental set up (Case of the NACA 0015 profile)

The transversal electric resistivity of the different dielectric materials used in our experiments varies from $10^{15}$ to $10^{18} \Omega / \mathrm{cm}$. Indeed, our study isn't focused on the dielectric behavior of these materials which are used only as discharge support. These materials are chosen with a large electric resistivity in order to obtain a stable electric discharge.

\section{Electric Characteristics}

We have drawn the linear current density-electric field characteristics in order to have an idea about the current values and especially to characterize the discharge regimes. In fact, discharge regimes are classified according to the current density values (Moreau et al. 2002). All measurements are made without any spark. Figures 2, 3, 4 and 5 show that for the cases of the printed plate, the Plexiglas plate and the NACA profile we obtained current density values of $1,8 \mathrm{~mA} / \mathrm{m}$ to $2 \mathrm{~mA} / \mathrm{m}$ while for the PTFE cylinder the maximum current density is of $0.8 \mathrm{~mA} / \mathrm{m}$. These values correspond to the "High spot" regime that's now called "CORONA" regime and which is the most stable discharge having the highest current.

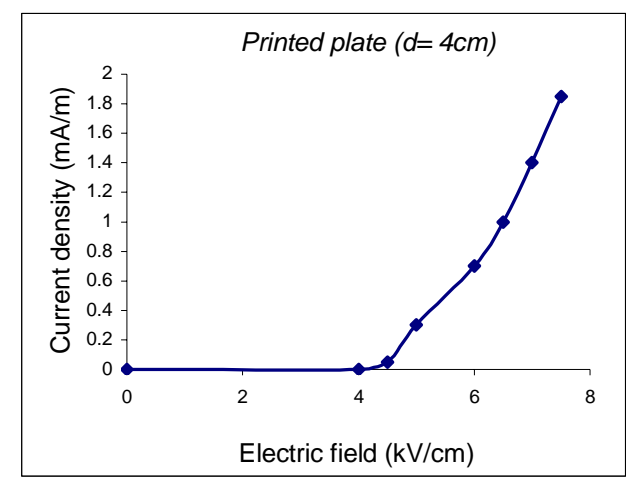

Fig. 2. Current density-electric field characteristics for a discharge at the surface of a printed plate (d: electrode gap) 


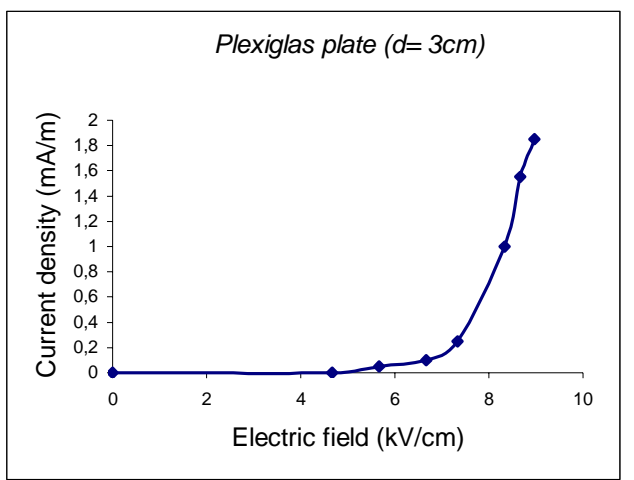

Fig. 3. Current density-electric field characteristics for a discharge at the surface of a Plexiglas plate (d: electrode gap)

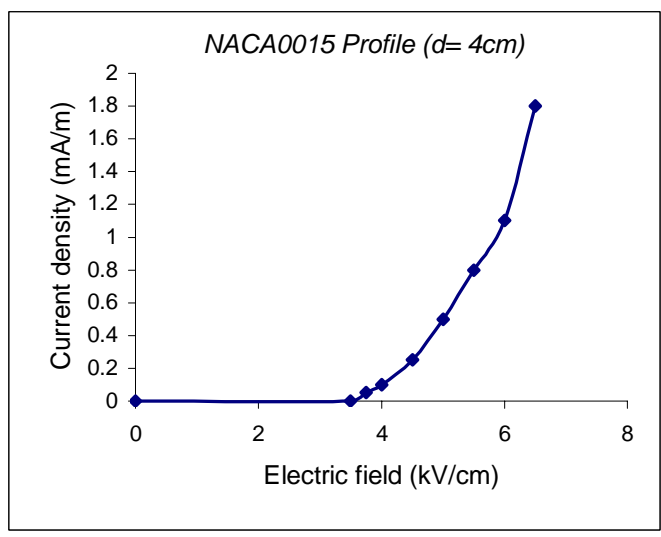

Fig. 4. Current density-electric field characteristics for a discharge at the surface of a NACA 0015 profile (d: electrode gap)

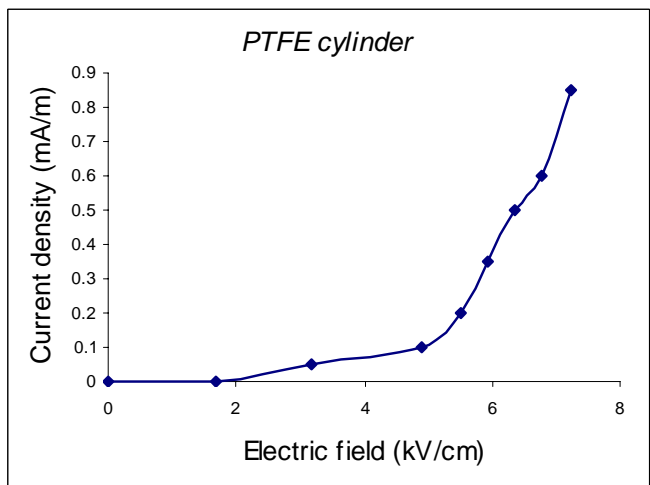

Fig. 5. Current density-electric field characteristics for a discharge at the surface of a PTFE cylinder

\section{IONIC Wind Velocity Profiles}

\subsection{Ionic wind}

The electric wind is due to the collisions between the ions that drift and the neutral particles in the electrode gap region (Moreau 2007). The plasma discharge can create an acceptable ionic or electric wind that is proportional to the corona current. However, although the electron velocity is much higher than the ion one, but we can neglect the role of electrons because their mass is very low compared with the ion one (Moreau 2007). The first expression of the electric wind velocity was given in 1961 by Robinson (1961):

$v_{G}=k \times \sqrt{\frac{i}{\rho \mu}}$

where $k$ is a constant that depends mainly on the electrode geometry, $i$ the time-averaged discharge current, $\rho$ the gas density and $\mu$ the ion mobility. This shows that the electric wind velocity is proportional to the square root of the current (Moreau 2007).

In 1993, the expression of Robinson was completed by Sigmond and Lagstadt (Sigmond 1993):

$v_{G}=\sqrt{\frac{i d}{\rho \mu A_{G}}}$

with $d$ the electrode gap and $A_{\mathrm{G}}$ the discharge crosssection.

\subsection{Velocity profiles}

The measurement of the electric wind, created above the surface of a dielectric material, enables us to evaluate the dynamic effect of the discharge and then judge its effect on the airflow control. Moreau (2007) confirmed that the works on airflow control by electrical discharges dealt with de coronas.

\subsubsection{Velocity profile at the surface of PMMA plate}

We present in Fig. 6 the velocity profile for a voltage of $25 \mathrm{kV}$ and for two $\mathrm{x}$ values. The corona current is equal to $120 \mu \mathrm{A}$. The maximum velocity is obtained at $\mathrm{x}=5 \mathrm{~mm}$ and $\mathrm{y}=1.4 \mathrm{~mm}$. We observe that the electric wind velocity is more important near the plate and it decreases when we move away from the wall. Downstream the discharge, when we move far from the anode, the velocity is less important.

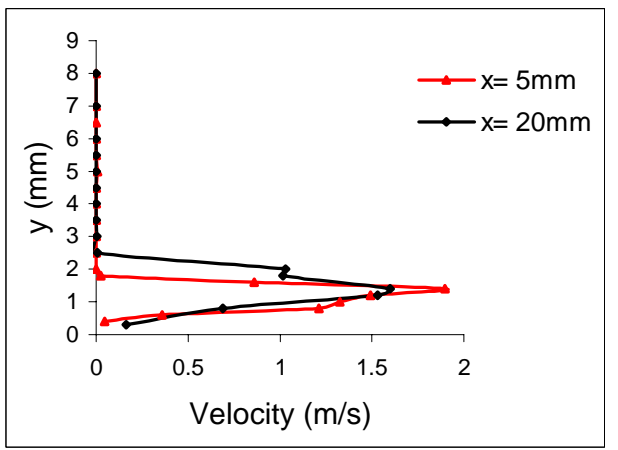

Fig. 6. Ionic wind velocity profiles for a PMMA actuator for two $\mathrm{x}$ values

A study done by Léger et al. (2002) showed, for a close case but with electrodes length of $30 \mathrm{~cm}$ and a current of $250 \mu \mathrm{A}$, that at $10 \mathrm{~mm}$ upstream the cathode $(\mathrm{x}=20 \mathrm{~mm})$ they obtained a maximum velocity of $1.6 \mathrm{~m} / \mathrm{s}$. In our case, in spite of the lower current value we have obtained 
almost the same velocity $(1.59 \mathrm{~m} / \mathrm{s})$, so the smaller electrode length and inter-electrodes gap can give a comparable ionic wind.

\subsubsection{Velocity profile at the surface of a printed plate}

For the printed flat plate, when the applied voltage is equal to $27 \mathrm{kV}$ and the current is $200 \mu \mathrm{A}$, the maximum velocity $\mathrm{U}_{\max }$ is located at $10 \mathrm{~mm}$ downstream the anode and at $\mathrm{y}=$ $2.5 \mathrm{~mm}$. We obtained the smallest velocities for the greater $\mathrm{x}$ values when we are at the vicinity of the cathode (Fig. 7).

When the applied voltage is $29.5 \mathrm{kV}$, we observe that the velocity is maximum at $\mathrm{x}=5 \mathrm{~mm}$ and $\mathrm{y}=1.3 \mathrm{~mm}$ (Fig. 8). When we move away from the anode at the direction of positive $\mathrm{x}$, the ionic wind becomes lower and the maximum velocity is reached at greater values of $y$. Indeed, this is due to the diffusion phenomenon of the momentum transferred from the plasma to the air.

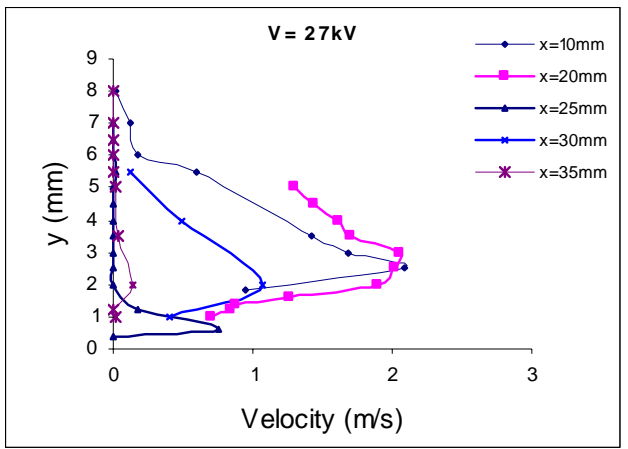

Fig. 7. Ionic wind velocity profiles for a printed flat plate for different $x$ values (the applied voltage is $27 \mathrm{kV}$ )

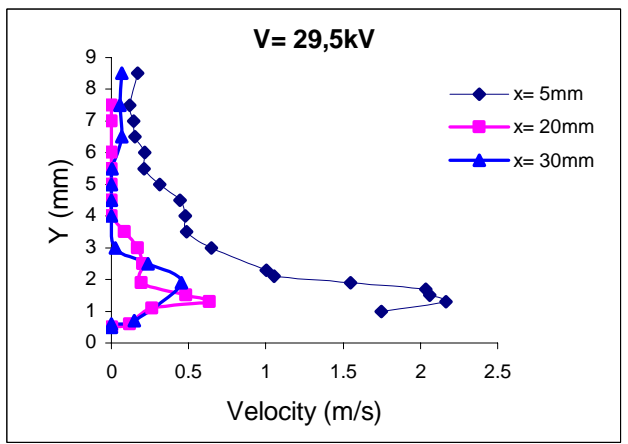

Fig. 8. Ionic wind velocity profiles above an actuator of printed flat plate for different $\mathrm{x}$ values (the applied voltage is $29.5 \mathrm{kV}$ )

\subsubsection{Velocity profile at the surface of a NACA 0015}

Figure 9 shows the velocity profiles for a fixed position downstream the anode $(\mathrm{x}=30 \mathrm{~mm})$ and for three corona current values. We note that the most important velocity is obtained with the highest corona current so the velocity increases with the current. Also, you can see that when the current is equal to $0.26 \mathrm{~mA}$ the maximum electric wind is found at $\mathrm{y}=1.8 \mathrm{~mm}$, whereas, for $\mathrm{i}=0.4 \mathrm{~mA}$ we observe that $U_{\max }$ is obtained at lower $y(y=0.3 \mathrm{~mm})$, indeed when the discharge current increases, the electric wind becomes closer to the surface.

This is in perfect agreement with the Robinson's relation given in "equation (1)". A previous work (Mestiri 2008) shows that the ionic wind velocity increases with the current.

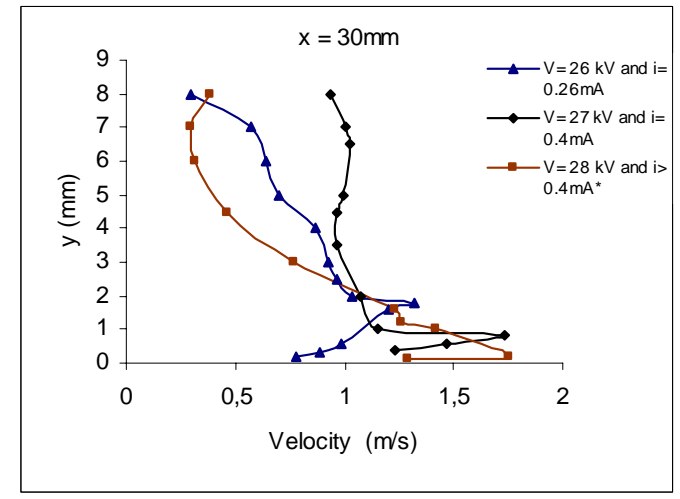

Fig. 9. Ionic wind velocity profiles for an actuator at the surface of NACA0015 (*the current is limited at $0.4 \mathrm{~mA}$ )

Figure 10 shows typical velocity profiles above a plasma actuator, for two $\mathrm{x}$ values, when the applied high voltage is to $0.4 \mathrm{~mA} \mathrm{~V}=28 \mathrm{kV}$. These profiles show clearly a velocity decrease when we move away from the anode. The maximum velocity $\mathrm{U}_{\max }$ is reached at $\mathrm{x}=10 \mathrm{~mm}$ and at $\mathrm{y}=0.2 \mathrm{~mm}$, this value is about $3.2 \mathrm{~m} / \mathrm{s}$ which is effective for the airflow control at the profile surface.

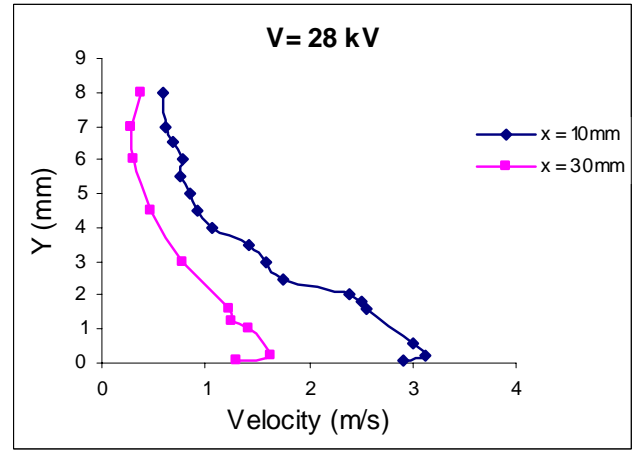

Fig. 10. Ionic wind velocity profiles for an actuator at the surface of NACA0015

\subsubsection{Velocity profile at the surface of a PTFE cylinder}

According to the profiles presented on Fig. 11, we observe an electric wind increase with the voltage. The ionic wind is proportional to the voltage which is approved by Mestiri et al. (2008).

Velocity profiles made for two applied voltage $(\mathrm{V}=31.5$ $\mathrm{kV}$ and $\mathrm{V}=32 \mathrm{kV}$ ), and for different $\mathrm{x}$ values, show that the height of the maximum velocity increases with the $x$ values (Fig. 12 and Fig. 13). Thus we can say that the diffusion phenomenon of the momentum transferred from the plasma to the air exists at the surface of the cylinder, which was not inevitably obvious due to the geometry. 


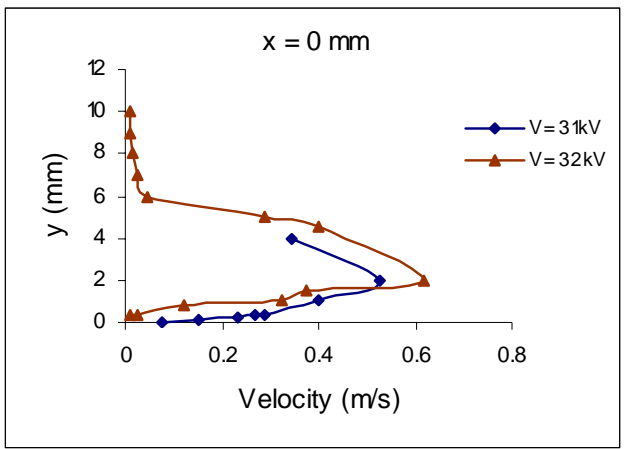

Fig. 11. Ionic wind velocity profiles above a plasma actuator at the surface of a PTFE cylinder

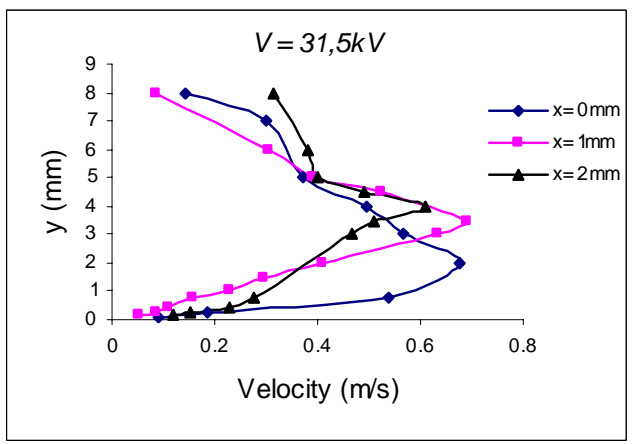

Fig. 12. Ionic wind velocity profiles above a plasma actuator at the surface of a PTFE cylinder for different $x$ values

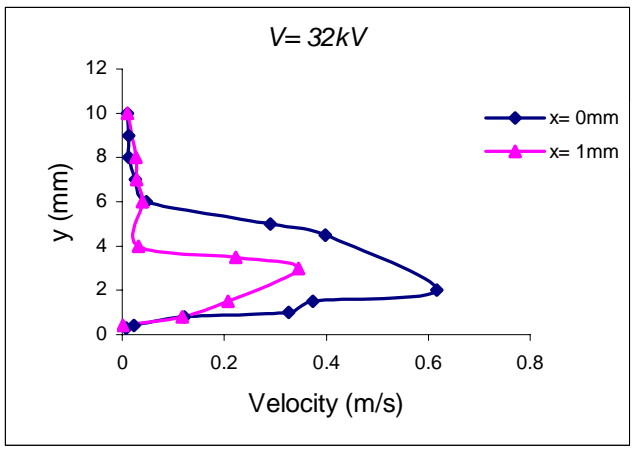

Fig. 13. Ionic wind velocity profiles above a plasma actuator at the surface of a PTFE cylinder for different $\mathrm{x}$ values

\section{CONCLUSION}

Through our experimental study of the corona discharge we have characterized some plasma actuators. We notice that we obtained the "High spot" regime for all studied supports, this shows that the discharge is stable and has high currents. Since the ionic wind velocity evolution in boundary layer gives a clear idea about the actuator effectiveness for the airflow control, we made the electric wind velocity profiles. We observe that the actuator at the surface of the NACA0015 produces an ionic wind whose velocity can reach a value of the order of $3.2 \mathrm{~m} / \mathrm{s}$. Also, results show that for the printed plate actuator the maximum electric wind is of $2.5 \mathrm{~m} / \mathrm{s}$, while it is smaller above the surface of a
Plexiglas plate where it is equal to $2 \mathrm{~m} / \mathrm{s}$. This may be caused by the small inter-electrodes gap which can limit the stability of the discharge to less significant voltage values, for the Plexiglas plate the voltage is of $25 \mathrm{kV}$, while we worked with a voltage of $27 \mathrm{kV}$ and $29.5 \mathrm{kV}$ for the printed plate. Otherwise for the cylinder, we justified the existence of an ionic wind at the surface of this little conventional profile for a corona discharge; however the measured ionic wind velocity is lower than the other studied supports which is due surely to its geometry. For all studied cases, we observe that when the $\mathrm{x}$ value increases, the airflow increasing is closer to the wall. For the NACA 0015 profile we notice that the induced ionic wind is nearer the wall when the corona current increases. Comparison of these studied actuators shows that the maximum ionic wind velocity is obtained with the NACA 0015 profile, so this actuator is the most effective for the airflow control. This is due to the geometry of the NACA0015 profile that is characterized by a curved surface, this geometry seems to be a potential barrier which induces a more stable discharge with large current values. Besides, the varnished wood surface certainly improves the electric resistivity of the discharge support, and thereafter it improves the discharge formation conditions. For the cases of the NACA profile and the printed plate, the electrodes are distant by $40 \mathrm{~mm}$ but the discharge substrate material is different, so the varnished wood stabilizes the discharge and supports greater ionic wind velocity. However, the printed plate and the Plexiglas plate actuators are sources of a considerable electric wind.

As a continuation of this work we will characterize these actuators in presence of a free airflow, so we will do PIV (Particle Image Velocimetry) visualizations and other measurements that put forward the effect of the external airflow on the discharge. Besides, under our collaboration with the LEA Laboratory, Poitiers, France, we will measure the lift and the drag forces in order to quantify the drag reduction or/and the lift enhancement.

\section{ACKNOWLEDGMENT}

We would like to thank all Members of the two laboratories: Laboratory of Thermal and Energetic Systems Studies (LESTE) at the National School of Engineering of Monastir, TUNISIA and Laboratory of Aerodynamic Studies (LEA) at the University of Poitiers, FRANCE, for their contributions and their help in order to realize this experimental study.

\section{REFERENCES}

Artana, G., G. Desimone and G. Touchard (1999). Study of the changes in the fow around a cylinder caused by electroconvection. Inst. Phys. Conf. Ser., Proc. Electrostatics'99, (163), 147-151.

Artana, G., J. Dadamo, G. Desimone and G. Diprimio (2000). Air fow control with electrohydrodynamic actuators. Proceedings of the second International Workshop on Conduction Convection and Brakdown in Fluids, Grenoble, 190-194.

Corke, T.C., C. He and M.P. Patel (2004). Plasma Flaps and Slats: an application of weakly-ionized Plasma 
actuators. American Institute of Aeronautics and Astronautics, Portland, Oregon, 28 Juin- 1 Juillet 2004, Paper 2004-2127.

Corke, T. and M. Post (2004, January). Overview of Plasma Actuators: Concepts, Optimization, and Applications. AIAA Paper 2005-0563.

Desimone, G., G. Diprimio and G. Artana (1999). Modifications to the fow field around a cylinder by means of electrodes placed on its surface. Proceeding of SFE 99, Poitiers, France, 80-84.

Forte, M., J. Jolibois, E. Moreau and G. Touchard (2006). Optimization of a Dielectric Barrier Discharge actuator stationary and non-stationary measurements of the induced flow velocity- Application to airflow control. $3^{\text {rd }}$ AIAA Flow Control Conference, San Francisco, California, AIAA 2006-2863.

He, C., T.C. Corke and M.P. Patel (2007). Numerical and experimental analysis of plasma flow control over a hump model. $45^{\text {th }}$ Aerospace Sciences Meeting, January 8-11, Reno, Nevada, paper 2007-0935.

Kimmel, R.L., J.R. Hayes, J.A. Menart and J. Shang (2004, January). Effect of Surface Plasma Discharges on Boundary Layers at Mach 5. AIAA Paper 20040509.

Léger, L., E. Moreau and G. Touchard (2002). Electrohydrodynamic airflow control along a flat plate by a DC surface corona discharge- Velocity profile and wall pressure measurements. American Institute of Aeronautics and Astronautics, , St. Louis, Missouri, 24-26 June 2002, Paper 2002-2833.

Léger, L., E. Moreau, G. Artana and G. Touchard (2001). Influence of a DC corona discharge on the airflow along an inclined flat plat. J. Electrostatics, 51- 52, 300- 306

Mahanti, N.C. and P. Gaur (2009, January). Effects of varying viscosity and thermal conductivity on steady free convective flow and heat transfer along an isothermal vertical plate in the presence of heat sink. Journal of Applied Fluid Mechanics, 2(1), 23-28.

Merriman, S.E. Ploenjes, P. Palm, and I. Admovich (2001, August). Shock Wave Control by Nonequilibrium Plasmas in Cold Supersonic Gas Flows. AIAA Journal, $39(8)$.

Mestiri., R., R. Hadaji and S.B. Nasrallah (2008). The electrical discharge as a source of a mechanical energy. Desalination, 220, 468- 475.
Moreau, E. (2007). Airflow control by non-thermal plasma actuators. J. Phys. D. Appl. Phys. 40, 605636.

Moreau, E., L. Léger and G. Touchard (2002). Contrôle de l'écoulement d'air autour d'un obstacle à l'aide d'une décharge électrique ou plasma- Application à l'aéronautique. GEVIQ 2002, Aerodynamic Studies Laboratory, Poitiers University.

Patel, M.P., T.T. Ng, S. Vasudevan, T.C. Corke, M.L. Post, T.E. McLaughlin and C.F. Suchomel (2008). Scaling effects of an aerodynamic plasma actuator. Journal of Aircraft, 45(1), 223- 236.

Post, M.L. and T.C. Corke (2006). Separation Control Plasma Actuators, Dynamic Stall Vortex Control on Oscillating Airfoil. American Institute of Aeronautics and Astronautics Journal, 44(12).

Rahmati, A. R. and M. Ashrafizaadeh (2009). A generalized lattice Boltzmann method for threedimensional incompressible fluid flow simulation. 2(1), 71-95.

Robinson, M. (1961). Movement of air in the electric wind of the corona discharge. AIEE Trans. 80, 143150 .

Roth, J.R. (2003). Aerodynamic Flow Acceleration Using Paraelectric and Peristaltic Electrohydrodynamic Effects of a One Atmosphere Uniform Glow Discharge Plasma. Physics of Plasmas, 10(5), 2117-2126.

Samimy, M., I. Adamovich, B. Webb, J. Kastner, J. Hileman, S. Keshav and P. Palm (2004). Development and Characterization of Plasma Actuators for High Speed Jet Control. Experiments in Fluids, 37(4), 577-588.

Sigmond, R.S. and I.H. Lagstadt (1993). Mass and species transport in corona discharges. High Temp. Chem. Proces., 2, 221-229. 